\title{
Virtual Laboratory for Power Electronic Based Reactive Power Compensators
}

\author{
Resul COTELI, Ali Osman GOKCAN
}

\begin{abstract}
The practical application is important in engineering education. However, in some cases, such as fund deficiency, practical applications may not be possible. In addition, this case restricts closely to pursue the novel technologies. Depending on developments in power electronics and microprocessor fields, use of Flexible Alternating Current Transmission Systems (FACTS) devices have been becoming more common. Practical applications on these devices are insufficient in undergraduate education. This study presents a virtual laboratory application for power electronics based FACTS devices. The virtual laboratory for education of advanced compensation method is prepared by using MATLAB GUI. The all parameters belonging to the related circuit can be accessed via the prepared virtual laboratory. Over a visual interface, current, voltage and power values can be observed. Theoretical information about the related subject is also included in the prepared virtual laboratory. All possible applications can be done even if users do not know MATLAB Programming Language, GUI, any formula or command from Simulink. User can repeat the application as much as they want and observe results obtained from different parameter values.
\end{abstract}

Keywords: FACTS devices; power electronics based reactive power compensators; reactive power compensation; virtual laboratory

\section{INTRODUCTION}

Increasing need for energy due to modern industry not only increased the inclination to use sustainable energy resources but also caused studies in direction of using energy resources more efficiency and in better quality [1]. As the most common energy type, electrical energy also got its share from these studies. In order to increase the electricity energy efficiency and transmitting it with minimum losses, a stronger emphasis on the subject of reactive power compensation was given. However, traditional compensation systems are insufficient to increase the controllability, capacity and efficiency of power track capacity and efficiency for energy transmitting systems. For these reasons, conducted studies are now focused more on Flexible Alternating Current Transmitting Systems (FACTS) [2].

Laboratory work is an indispensable part of engineering education. Theoretical knowledge is acquired by practicing in laboratory studies. Laboratory works are the most common way of training for the students to gain experience. There are several physical limitations of economical and convenient alternatives to actual laboratory works [3].

For reactive power compensation, which is an important subject for power electronics, there can be difficulties in learning it due to FACTS consisting of intangible concepts, including complicated processes on related calculations, having insufficient capabilities on laboratory and application. For this reason, on degree and graduate degree courses, using visual interface applications for reactive power compensators will make these concepts more tangible and make the subject easier to learn efficiently. Furthermore, since an immediate feedback can be received by GUI, (Graphical User Interface) based applications one can save from learning time, repeat missing classes and classes that could not be learnt by the students actively, making it easier for the instructor and more pleasurable [3].

When the interfaces used in the purpose of education are examined, it is seen that studies based on MATrix LABoratory (MATLAB) are seen quite frequently. Studies including interface designs related to various technical subjects belonging to Electric and Electronic engineering are given below in an order.

Ref. [4] depicted the importance of user interfaces used in their program in an educational aspect. For this purpose, they realized an interface design to improve environmental control system applications. In Ref. [5], a study is done in the direction of learning theoretical concepts on the subject of processing signals with visual animations and the effects of this study on students are mentioned. A virtual electrical machine laboratory for electrical engineering lab courses has been developed in Ref. [3]. In this study, an example of application was presented for the control of synchronous motor and noload and blocked rotor test of synchronous generator. In Ref. [6], they explained the importance of virtual laboratories in engineering education, did a comparison between a simulation of a laboratory and distant laboratories with internet access. In their study, they explained the advantages and disadvantages of virtual laboratories in engineering education. A fault simulation tool for power system analysis was prepared by Ref. [7]. With this tool, students can do the analysis of short circuit currents on energy transmission lines. Furthermore, students can observe the related current and voltage graphics related to the subject and learn the concepts easily. An application on the subject of converter circuits and correcting power factor was presented in Ref. [8]. They depicted the possibility to manage the circuits prepared in MATLAB Simulink via a designed interface based on MATLAB GUI. Ref. [9] presented a virtual laboratory for power electronics converters. Ref. [10] prepared a MATLAB GUI based interface for students in order to learn more easily the surge arrester current tests. In their study, surge arrester voltage tests made it possible to simulate long-term strength tests and execution duty tests through an interface. In tests that were done on more than 30 students, positive feedback was received. An educational tool for the analysis of DC machines was presented in Ref. [11]. The results of this study show that students can easily observe results of DC machines.

In this study, a MATLAB GUI based virtual laboratory for Flexible Alternating Current Transmission System Devices (FVLD) is presented; due to the students, 
and for a better understanding of the reactive power compensator objectives, traditional methods of reactive power compensator and power-based methods have been used. Furthermore, it is aimed to reach a quick and correct result on problems with solutions that take a long time. For this purpose, MATLAB Simulink models related to traditional methods, power electronics based devices are used, and these models are associated with a user interface prepared on MATLAB GUI. By doing so, it was made possible to track graphics and results belonging to simulation models from the interface screen. In this study, a simulation model is used belonging to six FACTS devices named Static Var compensator (SVC), Static Synchronous Compensator (STATCOM), Distribution Static Synchronous Compensator (D-STATCOM), Static Series Synchronous Compensator (SSSC), Thyristor Controlled Series Capacitor (TSCS) and Unified Power Flow Controller (UPFC). Users can observe certain results prepared on MATLAB GUI belonging to these models on an interface. Furthermore, working principle of these models and circuit models are places on the interface and information related to these can easily be accessed with buttons on the interface.

\section{REACTIVE POWER COMPENSATION}

The reactive power is one of the fundamental power quality problems. Unless this problem is eliminated, it can cause disadvantages such as lowering the power factor of the system, reduction of energy losses and efficiency, excessive neutral current, overheating on system components such as transformer, bus bar and cables and incidents of resonance. To eliminate these drawbacks, reactive power should be compensated. With balancing inductive and capacitive loads on the energy system and the necessary and built systems to return reactive power back to the source or the process of meeting the required reactive power of the load using certain techniques is named as reactive power compensation $[12,13]$.

Compensation types to be used change depending on the local arrangement of the consumer. While it is easy to compensate reactive power of the inductive consumers with individual compensators, on the other hand actual total demand of the constantly connected capacitors can increase. For this reason, complex compensators offer a wider variety of choices. Lightening of a plant can be solved by a group compensator and the remaining consumers can be controlled with an automatic controlled central compensator $[14,15]$.

Traditional compensation systems can be sufficient in terms of slow load changes and constantly on situations related to the control of voltage amplitude, voltage phase angle and line impedance. However, they are insufficient on dynamic system conditions [16]. With the rapid advances on solid-state half inductive technologies, in order to control AC systems more efficiently, devices that include power electronic components are improved. The devices that are named as FACTS take place of the traditional compensation systems in controlling power systems accurately and rapidly [17].

\section{FACTS DEVICES}

FACTS is defined by American Institute of Electric and Electronic Engineering (IEEE) as static hardware or power or a system based on power electronics to make it easier to control power systems and is used to increase power transmission capacity [17]. Main applications of the FACTS devices can be put in order as below:

- Increasing the power transfer capability and system stability of transmission systems.

- $\quad$ Providing the power flow on the line.

As the FACTS devices are being used, many execution functions that could not be actualized in the past can now be easily performed. Some of these functions are as follows:

- Control of the power on transmission lines,

- Using transmission lines on full capacity without overloading,

- Relieving overload transmission lines in order to decrease system losses,

- Increasing system security and stability,

- Preventing consecutive system interruptions by limiting problems and hardware defect effects on the system,

- Damping oscillations on power systems [2].

Power electronics based compensators can be categorized into three main groups according to their connection type: Series, parallel and series - parallel. The compensators according to the connection type are explained below.

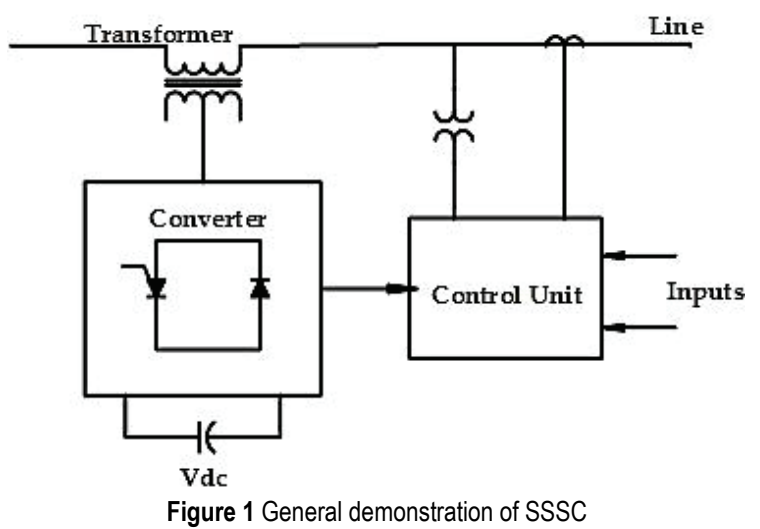

\subsection{Series Compensators \\ 3.1.1 Static Synchronous Series Compensators}

Static Synchronous Series Compensator (SSSC) is a synchronized voltage source connected to the transmission line in series as shown in Fig. 1. By injecting an appropriate voltage to the transmission line, active impedance of the line can be changed. Furthermore, while a capacitor connected in series can create a voltage at $90^{\circ}$ lag phase according to the line current, line inductance can create $90^{\circ}$ lead phase according to the line current. As a result, in order to reduce the effect of the line inductance, a capacitor connected in series should be added. Working principle of SSSC depends on this capacitor to be able to create a $90^{\circ}$ lag phase voltage according to the line current. Normally, output voltage of 
SSSC has a lag phase of $90^{\circ}$ compared to the line current and an active compensation in series is connected [18].

\subsubsection{Thyristor Controlled Series Capacitor}

Thyristor Controlled Series Capacitor (TCSC) is a typical series FACTS device that can control reactance value. This device is connected in series to transmission lines to compensate the impedance of the line. By doing so, entire bus bar admittance structure of the system can be changed. TCSC, while increasing power transfer capacity on the line, also reduces the reactive power losses. In order to regulate transient stability, it reduces the line reactance and provides improvements on voltage regulation and system stability on the line [19]. Schematic diagram of TCSC is shown in Fig. 2. TCSC device can work on four modes as blocking mode, by-pass mode, capacitive boost mode and inductive boost mode [20]:

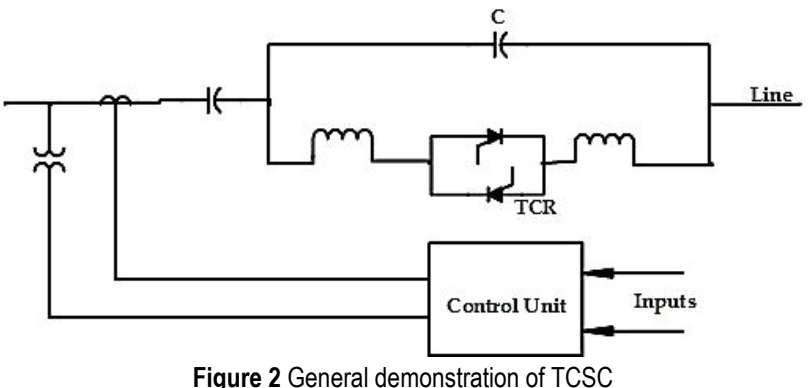

As seen in Fig. 2, permanent capacitor is connected with two thyristor valves connected in parallel in opposite directions that can do transmission on both half periods and a reactor connected in series to the thyristor valve.

\subsubsection{Thyristor Controlled Series Capacitor}

Thyristor Controlled Series Reactor (TCSR) is an inductive reactance compensator connected in series. In principle, it has the purpose of acquiring variable and inductive serial reactance. While the trigger angle is $180^{\circ}$, thyristor is turned off and uncontrolled reactor works as an error current limiter. When it is below $180^{\circ}$, inductance reduces until the angle reaches $90^{\circ}$. In this interval, system consists of two shunt reactors [21]. General demonstration of TCSR is depicted in Fig. 3.

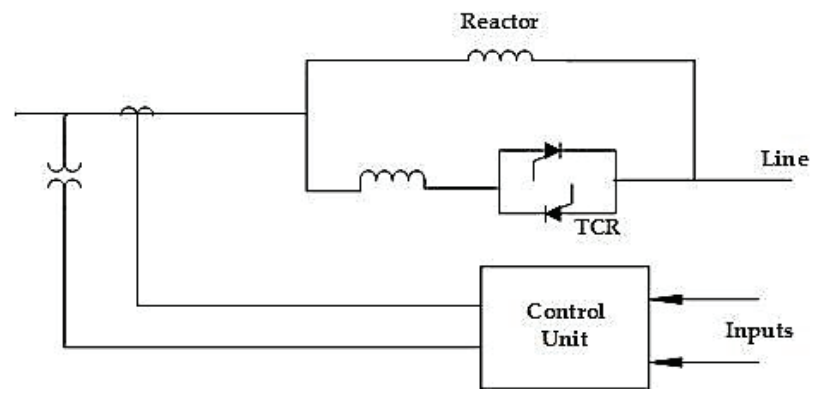

Figure 3 General demonstration of TCSR

\subsubsection{Thyristor Switched Series Capacitor}

Structure of Thyristor Switched Series Capacitor (TSSC) is the same with TCSC. However, working principle of TSSC is in the form of including reactor groups into the circuit completely or removing them from the circuit. By doing so, both costs and switching losses are reduced [2].

\subsubsection{Thyristor Switched Series Reactor}

There is no difference between a TSSR and TCSR structure. The working principle includes the reactance with a connected shunt into the circuit somehow and excluding it [18].

\subsection{Parallel Compensators}

In parallel compensation, FACTS devices is connected to shunt (in parallel) to the power system and works as a controllable current source.

\subsubsection{Static Var Compensator}

This device is the first emerging FACT device. For the arc furnace compensation, it was developed at the start of the 1970's and then adapted to transmission applications with improvements as time goes on [22]. Generally, there are two types of Static Var Compensator (SVC). First SVC type consists of a TCR and a capacitor connected in shunt. Second type SVC is made of a TCR and a capacitor connected to it in series and named as thyristor switched capacitor (TSC). SVC structure made of TCR and capacitors with a connected shunt are used commonly in applications. Ideal SVC is defined as a controller that can respond quickly and equally in voltage to the reference voltage without an active or reactive power loss [23]. Fig. 4 shows schematic representation of a SVC.

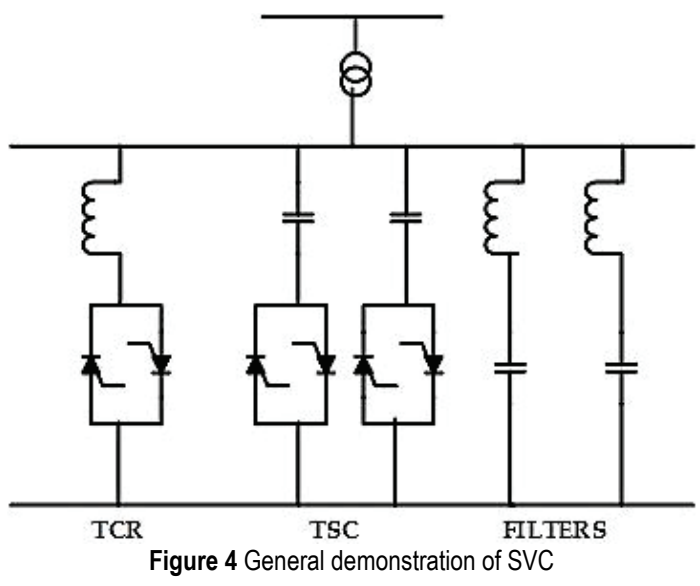

Working principle of the SVC is based on obtaining variable shunt impedance by putting capacitors and/or reactors in and out of the grid in accordance with the measured triggering angles. With appropriate triggering, on the bus bar where the SVC is connected, reactive power compensation can be done on a wide interval from maximum capacitive reactive power values to maximum inductive reactive power values [24]. 


\subsubsection{Static Synchronous Compensator}

Static Synchronous Compensator (STATCOM) is a FACTS device connected in parallel to transmission line. It is also named STATCOM or ASVC (Advanced Static Var Compensator). In an electric power system, STATCOM connected, as a shunt to bus bar giving the possibility to control parameters existing on the electricity system with controllability of its output, a FACTS device can do compensation rapidly by producing or consuming reactive power [25]. Working characteristics of STATCOM are the same as with synchronous condenser. Primary function of these devices is to regulate the transmission line at the connection point by absorbing/generating a controlled reactive current from the transmission line [26]. General circuit structure of STATCOM is given in Fig. 5. STATCOM consists of a connection transformer, DC-AC converter and a DC capacitor. It provides rapid amplitude and phase control of three phased voltages. Voltage difference across inductive impedance provides reactive power transfer between STATCOM and the system [25].

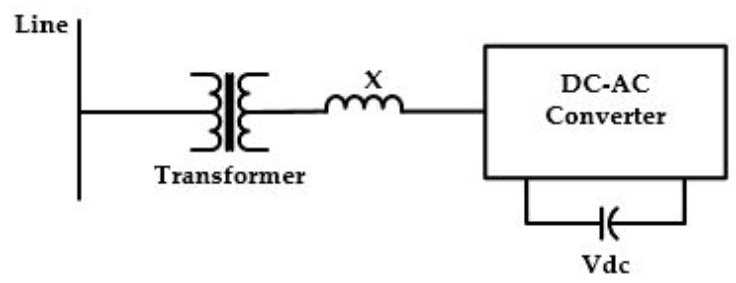

Figure $\mathbf{5}$ General circuit structure of STATCOM

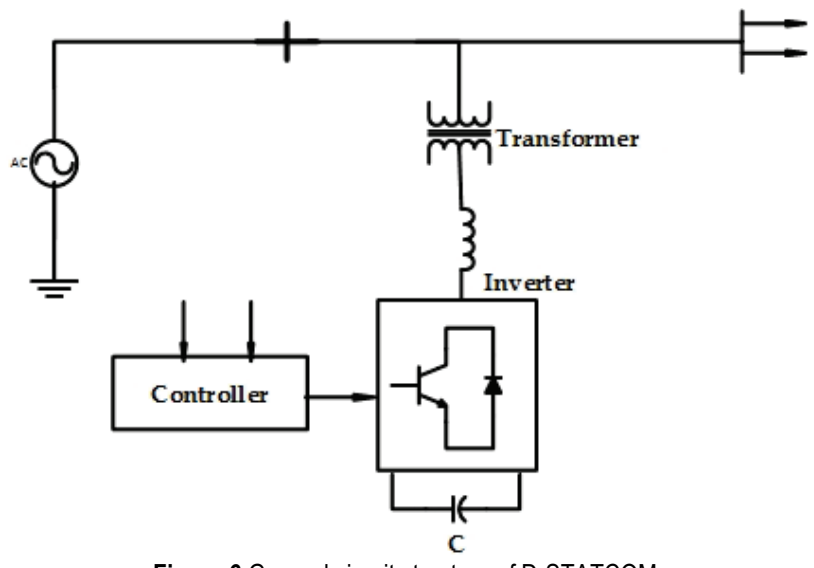

Figure 6 General circuit structure of D-STATCOM

\subsubsection{Distribution STATCOM}

Distribution STATCOM (D-STATCOM) is wellknown power electronics based compensator that provides low cost solutions. It is used for reactive power compensation in distribution systems. D-STATCOM, which is connected in parallel to transmission lines, can inject current to the system in order to reduce the harmonics and regulate reactive power. D-STATCOM applications are usually for changings that are too sensitive to fluctuations that occur on the system. In structure of D-STATCOM, voltage source inverters (VSIs) are used together with pulse amplitude modulation (PWM) in order to reduce the voltage fluctuations. With this, other modulation techniques and other converters can be used with STATCOM [27]. In Fig. 6, general circuit structure of D-STATCOM is presented.

\subsection{Series-Parallel Compensators}

Such compensators are a mixture of compensators in both series and parallel. These devices, while giving current to the system with its parallel section, also provide voltage to the line with its serial section. This compensator is explained in below.

\subsubsection{Unified Power Flow Controller}

General circuit structure of Unified Power Flow Controller (UPFC) is given in Fig. 7. UPFC is a FACTS device that works with a mutual DC capacitor and allows bi-directional power flow between a shunt connected to the transmission line of STATCOM (Converter1) and ends of SSSC (Converter2) connected in series on the line. UPFC can inject voltage on the transmission line without angular limitations and can control active and reactive power flow on the line. At the same time, each converter can perform shunt reactive compensation independently at its own output terminal [28].

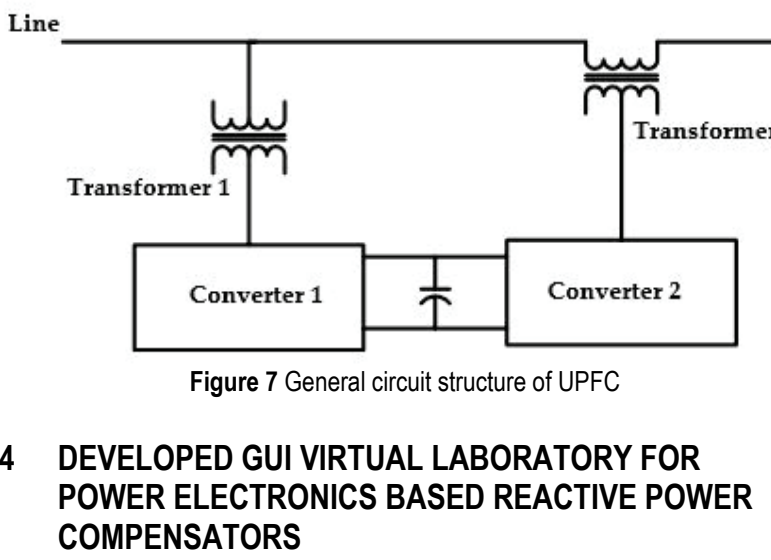

Graphical interface GUI can be prepared with two ways on MATLAB. In the first way, GUI can be prepared via a $\mathrm{m}$-file by using the programming codes, all events that are requested to happen on the design and interface are written by programmers with the necessary codes. Second way is, creating an interface with the help of MATLAB Guide. Here, objects similar to radio buttons, panels, listing boxes that are on the Guide device are benefited from. Interface design, which is done with the method of drag and drop, is associated with callbacks and requested events [29]. In this study, in order to establish a graphical user interface, Guide was used and a virtual laboratory was designed for education of FACTS devices. Designed interface consists of one primary screen and six sub-screens connected to the primary screen. Image of this primary screen on GUI working page is given in Fig. 8 and its image while operating is depicted in Fig. 9.

The homepage of the GUI is gathered under six subheads. These are STATCOM, SVC, D-STATCOM, TCSC, SSSC and UPFC. Requested heading can be opened after clicking it. 

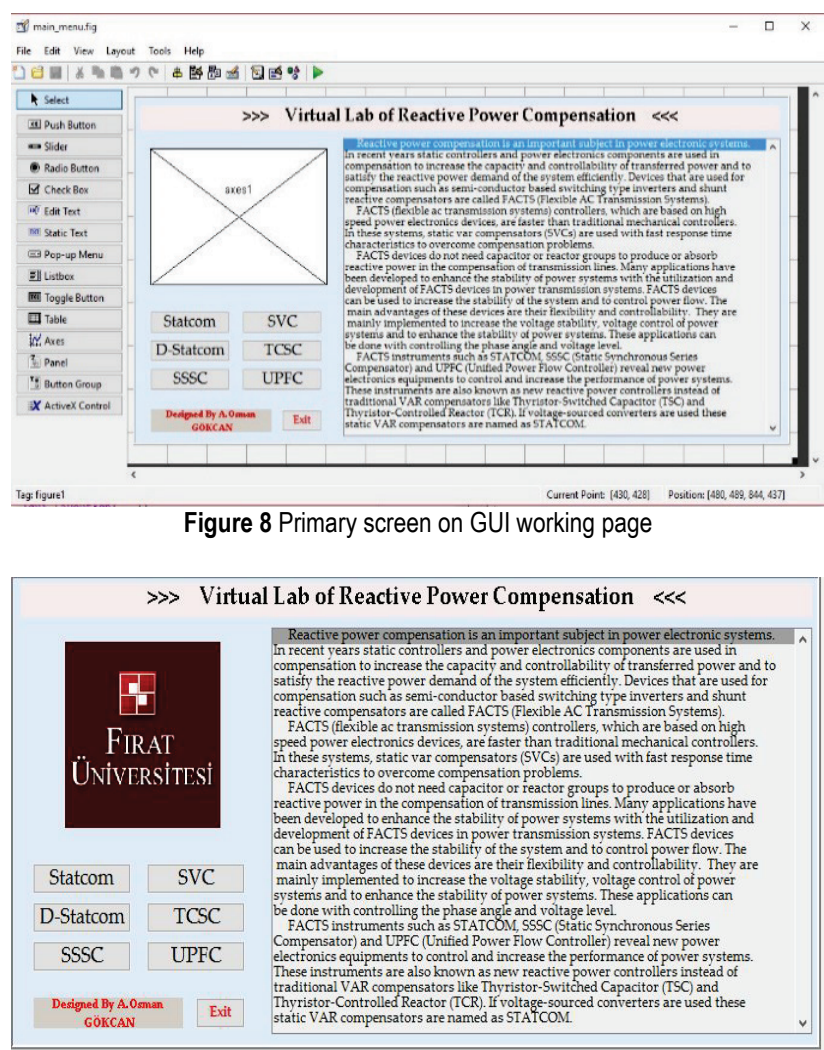

Figure 9 Home page of GUI working page

The prepared virtual laboratory includes information related to FACTS devices and reactive power compensators. User can acquire prior knowledge by reading this section about reactive power compensators and FACTS devices. To explain all the options that are on the sub-screens connected to the main page with the same properties. This information is general properties for the chosen sections of the device and not an explanation of the detailed circuit figure that is used during the simulation. Another section is "Basic Structure" under the informative section. This section is general view of the chosen device, or in other words, singular line figure. Under the singular line figure, there is a "CONTROL MENU". With the "Open Simulink File" button on this section, user can access a detailed figure, which was prepared on Simulink (circuit figure). Opened file with the $m d l$ extension is named as the model file and starts to work by clicking the button "Start the Simulation". Results can be monitored from the section "CIRCUIT SCOPE". The user can use button "Close Simulink File" if students wish to close the circuit, which appears after the circuit is opened. Users may use the "Description" button in order to see the detailed results of the simulated device and to learn more about how device works. When this button is clicked, a file prepared on Microsoft Word context will be opened. Furthermore, it can return to first values (default) belonging to the circuit and redraw the results with the "Reset" button. Two buttons that exist in all pages with a common feature are "Back" button that allows the user to return to the main page and "Exit" button that allows the user to exit from FDVL completely as shown in Fig. 9. When the STATCOM button on the main page is clicked, window in Fig. 10 comes up on the screen. For the control of simulation and STATCOM Simulink model, users can utilize the "STATCOM
CONTROL MENU" as shown in Fig. 10. Parameters under this section are gathered under three headlines:

- STATCOM controller: In this menu, two tasks as voltage regulation or reactive power compensation can be carried out. Point of common coupling voltage is controlled by selecting voltage regulation task in this menu. The aim of voltage regulation is to keep the point of common coupling voltage constant at its set point. The internal impedance is compensated with Droop parameter in $p u$. Reactive power or reactive current setpoint can be controlled in this heading.

- Lines: Under the line headline, L1, L2 and L3 line parameters and lengths of these lines can be controlled.

- STATCOM Capacitance: $C_{\mathrm{p}}$ and $C_{\mathrm{m}}$ parameters are used to adjust DC-link capacitor value of STATCOM in Simulink models. After theses parameters are entered, users can simulate STATCOM circuit for different capacitance values and monitor the results on the interface belonging to the circuit from the section of "CIRCUIT SCOPE".

Some results obtained under different operating conditions are given in Fig. 10. Amount of the delivered/absorbed reactive power by STATCOM can be observed when DC-link voltage is changed. Thus, the students can easily learn how STATCOM carries out reactive power compensation.

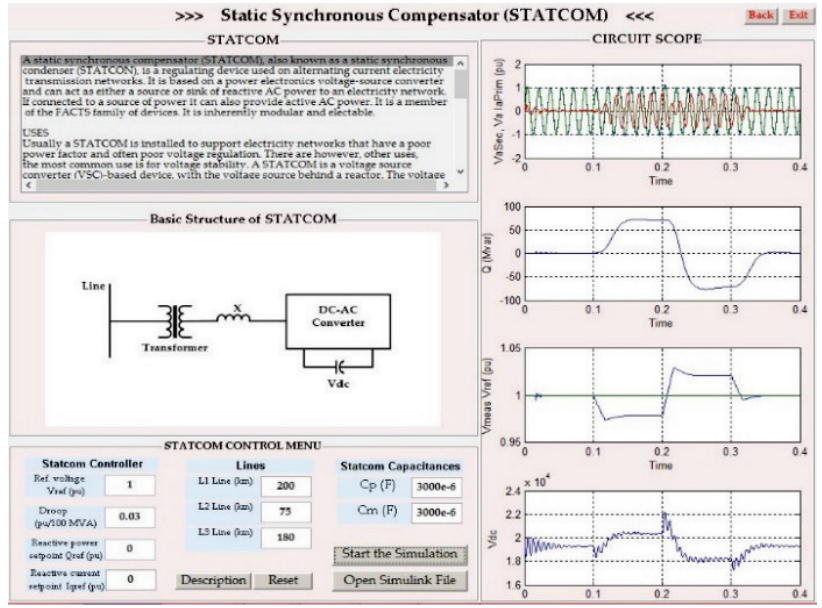

Figure $10 \mathrm{GUI}$ working page of STATCOM

When the D-STATCOM button on the main page in Fig. 12 is clicked, window shown in Fig. 11 comes up. Parameters in the DSTATCOM CONTROL MENU are gathered under three headings:

- Load: Feeder Line parameter under this heading controls line length, active power of load. $Q_{\mathrm{L}}$ and $Q_{\mathrm{C}}$ parameters controls the reactive power of the load.

- D-STATCOM Controller: The voltage on the connection point is controlled by AC voltage set point $V_{\text {ref }}$ parameter in $p u$ under this heading. In addition, $Q_{\text {ref }}$ and DC voltage setpoint parameters control reference reactive power DC-link voltage. When simulation model is run, it is observed that point of common coupling voltage is set value by absorbing or delivering required reactive power.

- D-STATCOM Capacitances: With the parameters in this heading, value of DC-link capacitors can be adjusted and changes on DC line voltage in accordance with these values can be observed. It is seen that the 
fluctuation in DC line voltage is decreased when value of DC line capacitors is increased.

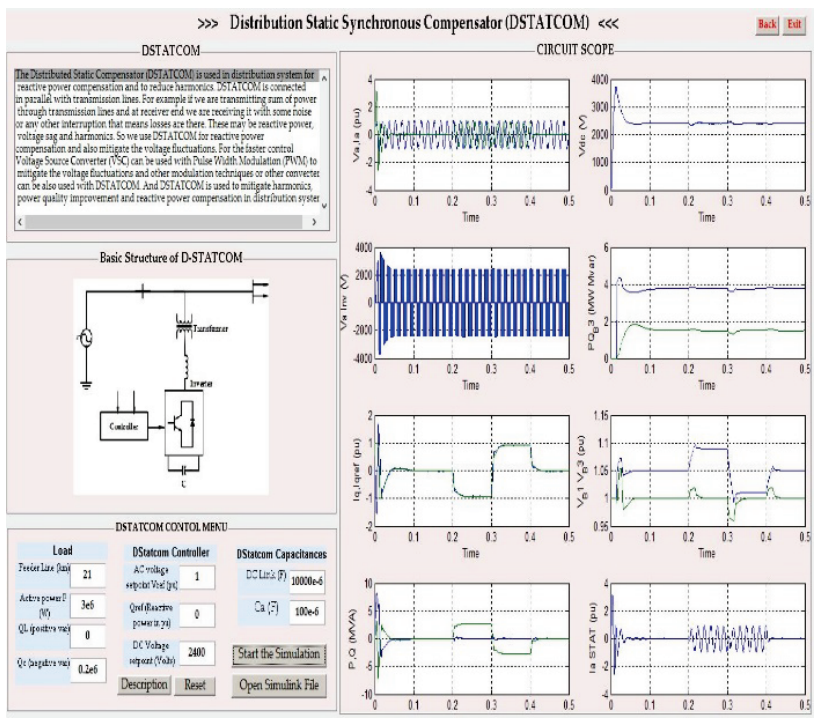

Figure $11 \mathrm{GUI}$ working page of D-STATCOM

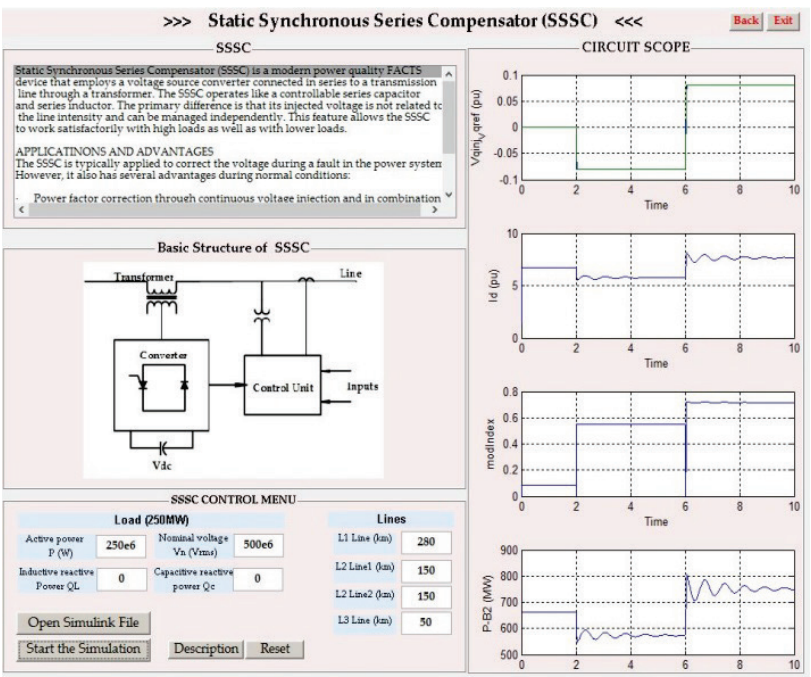

Figure 12 GUI working page of SSSC

When the SSSC button on the main page in Fig. 9 is clicked, a window is opened as shown in Fig. 12. Adjustable parameters of this window "SSSC CONTROL MENU" section are gathered under two headings:

When the SSSC button on the main page in Fig. 9 is clicked and a window is opened as shown in Fig. 12. Adjustable parameters of this window "SSSC CONTROL MENU" section are gathered under two headings:

- Load: With the Active Power parameter under this heading, active power value belonging to the load can be controlled. Inductive reactive power $\mathrm{Q}_{\mathrm{L}}$ parameter, capacitive reactive power $\mathrm{Q}_{\mathrm{C}}$ parameter and Nominal Voltage $V_{n}$ parameter control inductive reactive power value of the load, capacitive reactive power value of the load and nominal voltage value of the load, respectively.

- Lines: The lengths of the transmission lines are controlled by using L1 line and L2 line $(\mathrm{km})$ parameters in this heading. Fig. 12 shows performance of the SSSC under different operating conditions.
When the SVC button in Fig. 9 is clicked, window in Fig. 13 comes up on the screen. Parameters in this section are gathered under three headlines:

- 1TCR 3TSC: The inductance value of SVC is adjusted via $\mathrm{TCR}(\mathrm{H})$ parameter under the headline whereas capacitance values of SVC by means of TSC(C) parameter.

- Load: The nominal load voltage and frequency are controlled via Nominal voltage $V_{\text {n }}$ parameter and nominal frequency $f_{\mathrm{n}}$, respectively. The active power of the load is adjusted by Active power $P$ parameter pop-up. The results for load changing are given in Fig. 13.

- SVC Controller: The point of common coupling voltage can be kept constant at setpoint With Ref. Voltage $V_{\text {ref }}$ parameter under this headline. The internal impedance voltage drop is compensated with Droop parameter. The students can observe operation of the SVC for different values of TCR inductance, TSC capacitance and reference voltage.

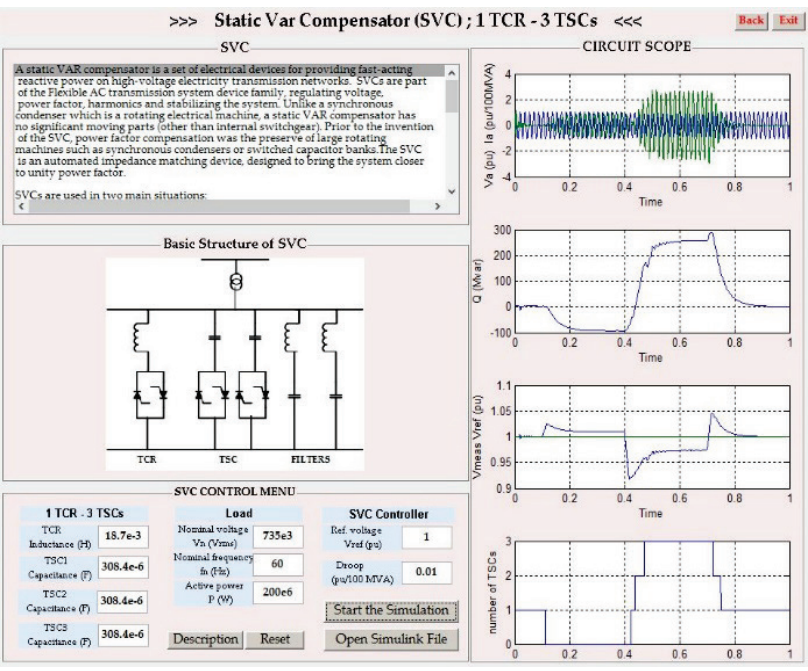

Figure 13 GUI working page of SVC

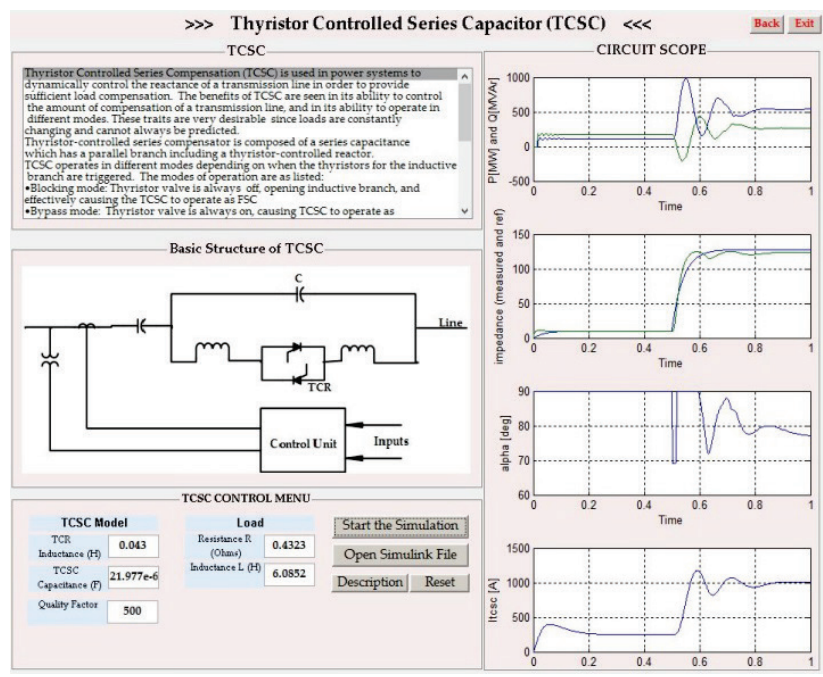

Figure $14 \mathrm{GUI}$ working page of TSSC

When the TCSC button in Fig. 9 is clicked, window in Fig. 14 comes up. Adjustable parameters in "TCSC CONTROL MENU" can be gathered under two headings as shown in Fig. 14.

- TCSC Model: TCR inductance parameter presents inductance value of TCSC whereas TSCS capacitance 
parameter depicts capacitance value of TCSC. In addition, Quality Factor parameter can be adjusted.

- Load: Resistance and Inductance parameters, control load resistance and inductance value of load, respectively. The students can observe operation of the TCSC for different values of TCR inductance, TCSC capacitance and load.

When the UPFC button shown in Fig. 9 is clicked, screen presented in Fig. 15 is opened. Parameters at the section of "UPFC CONTROL MENU" in Fig. 15 are gathered under three headlines. These headlines are:

- Converter1 (Shunt): The voltage at the point of the Converter1 (STATCOM) is kept at a stable value via voltage set point parameter under this headline. The reference reactive current is determined by using reactive current set point $I_{\text {qref }}$ menu. Two parameters are determined with the help of the mentioned menus.

- Lines: Under the Lines, with L1 line, L2 line, L3 line parameters, lengths of the transmission lines where UPFC is connected can be controlled.

- Converter2 (Series): From these parameters under this headline, Proportional gain $K_{\mathrm{p}}$ is determined proportional gain of Proportional + Integral (PI) controller whereas Integral gain $K_{\mathrm{i}}$ is integral gain of PI controller.

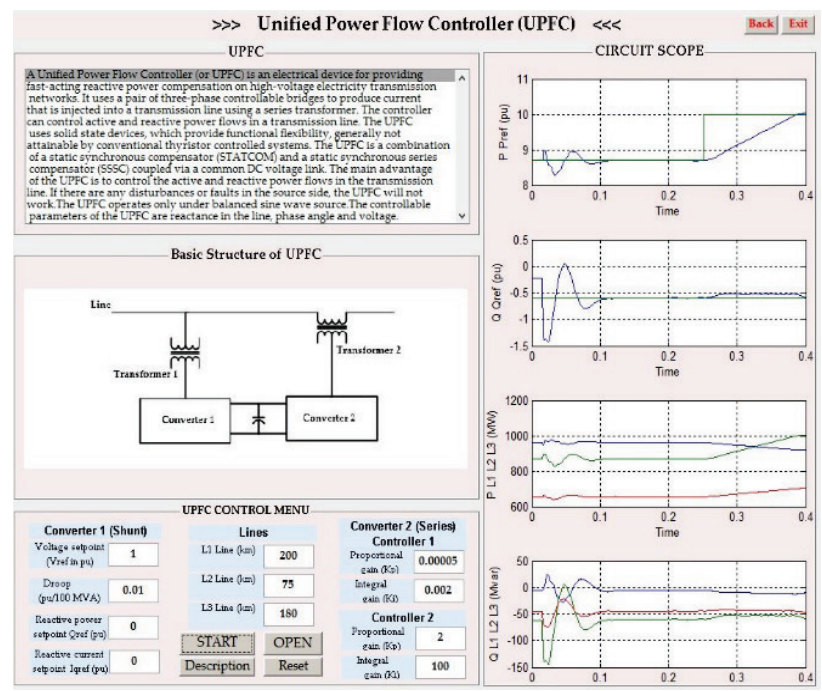

Figure $15 \mathrm{GUI}$ working page of UPFC

The students can observe effects of the PI controller parameters as well as change of line length.

\section{CONCLUSION}

In this study, a virtual laboratory application for power electronics based reactive power compensators is prepared. This virtual laboratory, which is prepared for compensation education, is carried out by using MATLAB GUI. In the study, a new simulation environment for circuits belonging to FACTS devices used on reactive power compensators is prepared. Over a visual interface, current, voltage and power values belonging to the circuit are shown in graphics. Users only need to use the interface and simulate the circuit related to the subject and change the parameters of the circuit to monitor new results. In the prepared virtual laboratory, aside from simulations belonging to the circuits of
FACTS devices, theoretical information about the related subject is also included. In this way, user, with the help of buttons on every interface, is able to reach the required information before and after the application with ease. All possible applications can be done even if the users do not know MATLAB Programming Language, GUI, any formula or command from Simulink. Another point is users are able to do their applications with at least one mistake on a visual platform. User can repeat the subject as much as they want and reiterate the subject by doing comparison between results with changed values.

\section{REFERENCES}

[1] Kececioglu, O. F., Acikgoz, H., \& Sekkeli, M. (2017). Advanced Configuration of Hybrid Passive Filter for Reactive Power and Harmonic Compensation. Springer Plus, 5(1), 1-20.

[2] Hingorani, N. (1993). Flexible AC transmission. IEEE spectrum, 30(4), 40-45. https://doi.org/10.1109/6.206621

[3] Tanyildizi, E., Orhan, A. (2009). A Virtual Electric Machine Laboratory for Synchronous Machine Application. Computer Applications in Engineering Education, 17(2), 187-195. https://doi.org/10.1002/cae.20133

[4] DeMoyer, R. \& Mitchell, E. (1999). Use of the MATLAB Graphical User Interface Development Environment for Some Control System Applications. 29th ASEE/IEEE Frontiers in Education Conference / San Juan, 7-11. https://doi.org/10.1109/FIE.1999.841577

[5] McClellan, J. H. \& Rosenthal, J. (2002). Animating Theoretical Concepts for Signal Processing Courses. Proceedings of the 2002 American Society for Engineering Education Annual Conference \& Exposition.

[6] Balamuralithara, B. \& Woods, P. C. (2009). Virtual Laboratories in Engineering Education: The Simulation Lab and Remote Lab. Computer Applications in Engineering Education, 17(1), 108-118. https://doi.org/10.1002/cae.20186

[7] Koc, S. \& Aydogmus, Z. (2009). A MATLAB/GUI based Fault Simulation Tool for Power System Education. Mathematical and Computational Applications, 14(3), 207217. https://doi.org/10.3390/mca14030207

[8] Kayisli, K., Tuncer, S., \& Poyraz, M. (2013). An Educational Tool for Fundamental DC-DC Converter Circuits and Active Power Factor Correction Applications'. Computer Applications in Engineering Education, 21(1), 113-134. https://doi.org/10.1002/cae.20455

[9] Altintaş, A. (2011). A GUI-based Education Toolbox for Power Electronics Converters Using MATLAB/Simulink and SimPowerSystems. International Journal of Electrical Engineering Education, 48(1), 53-65. https://doi.org/10.7227//JEEE.48.1.5

[10] Vahidi, B. \& Arabshahi, B. B. (2012). Teaching Current Tests on Surge Arresters to Undergraduate Students Using MATLAB Simulink. Computer Applications in Engineer Education, 20(1), 391-399. https://doi.org/10.1002/cae.20405

[11] Suryasen, K., Devadas, K. V., \& Harish, A. (2001). GUI based Testing Tool for DC Machine. International Journal of Computer Applications, 71(19), 53-65.

[12] Gelen, A. \& Yalcinoz, T. (2009). PI Control of Thyristor Switched Capacitor (TSC) and Thyristor Switched Reactorbased Static Var Compensator (TSR-based SVC). Journal of the Faculty of Engineering and Architecture of Gazi University, 24(1), 237-244.

[13] Kececioglu, O. F., Acikgoz, H., Yildiz, C., Gani, A., \& Sekkeli, M. (2017). Power Quality Improvement Using Hybrid Passive Filter Configuration for Wind Energy 
Systems. Journal of Electrical Engineering and Technology, 12(1), 207-216. https://doi.org/10.5370/JEET.2017.12.1.207

[14] Hofmann, W., Schlabbach, J., \& Just, W. (2012). Reactive power compensation: a practical guide. John Wiley \& Sons. https://doi.org/10.1002/9781119967286

[15] Kececioglu, O. F., Acikgoz, H., \& Sekkeli, M. (2016). Advanced configuration of hybrid passive filter for reactive power and harmonic compensation. SpringerPlus, 5(1) 1228. https://doi.org/10.1186/s40064-016-2917-7

[16] Moore, P. \& Ashmole, P. (1995). Flexible AC transmission systems. Power Engineering Journal, 9(6), 282-286. https://doi.org/10.1049/pe:19950610

[17] Edris, A. A. (1997). Proposed terms and definitions for flexible AC transmission system (FACTS). IEEE Transactions on Power Delivery, 12(4), 1.

[18] Alcan, Y., Öztürk, A., Dirik, H., \& Demir, M. Comparison of different heuristic algorithms for location and value determination of STATCOM providing minimum losses in power systems. Pamukkale University Journal of Engineering Sciences, 23(5), 550-558.

[19] Moghavvemi, M. \& Faruque, M. O. (2000). Effects of FACTS devices on static voltage stability. In TENCON 2000. Proceedings, 2, 357-362. https://doi.org/10.1109/TENCON.2000.888762

[20] Glanzmann, G. (2005). FACTS: flexible alternating current transmission systems. ETH Zurich.

[21] Yan, P. \& Sekar, A. (2005). Steady-state analysis of power system having multiple FACTS devices using line-flowbased equations. IEE Proceedings-Generation, Transmission and Distribution, 152(1), 31-39. https://doi.org/10.1049/ip-gtd:20041133

[22] Song, Y. H. \& Johns, A. Eds. (1999). Flexible ac transmission systems (FACTS) (No. 30). IET. https://doi.org/10.1049/PBPO030E

[23] Schauder, C. \& Mehta, H. N. (1993). Vector analysis and control of advanced static VAR compensators. IEE Proceedings $C$ (Generation, Transmission and Distribution), 140(4), 299-306. https://doi.org/10.1049/ip-c.1993.0044

[24] Torseng, S. (1981). Shunt-connected reactors and capacitors controlled by thyristors. In IEE Proceedings $C$ (Generation, Transmission and Distribution), 128(6), 366373). https://doi.org/10.1049/ip-c.1981.0059

[25] Zhu, Y. Q., Liu, W. H., Qiu, D. G., Liu, B., \& Lu, J. F. (2003). Simulation of Balancing Compensation of Unbalanced Load Based on Single Phase STATCOM. Power System Technology, 8, 011.

[26] Giroux, P., Sybille, G., \& Le-Huy, H. (2001). Modeling and simulation of a distribution STATCOM using simulink's power system blockset. In Industrial Electronics Society 2001. IECON'01, 2, 990-994. https://doi.org/10.1109//ECON.2001.975905

[27] Devaraju, T., Reddy, V. V., \& Kumar, M. V. (2010). Role of custom power devices in Power Quality Enhancement: A Review. International Journal of Engineering Science and Technology, 2(8), 3628-3634

[28] Karadeniz, K. (2010). Analysis of the Effects FACTSUPFC Device Effects on Electrical Power Systems. Master Thesis, Mersin University Department of Electrical and Electronics Engineering, Mersin.

[29] Kaplan, S. (2010). Design of a Visual Robotic Toolbox Using Graphical User Interface. Master Thesis, Mersin University Department of Electrical and Electronics Engineering, Mersin.

\section{Contact information:}

\section{Resul COTEL}

Firat University, Technology Faculty,

Department of Energy Systems Engineering

23119 Elazig, Turkey

rcoteli@gmail.com

\section{Ali Osman GOKCAN}

Celal Bayar University

Department of Electronic and Automation,

45100 Manisa, Turkey

aliosmangokcan@hotmail.com 